\title{
Simulations of Depth-Averaged Streamwise Velocity of Meandering Compound Channel using TELEMAC Modules
}

\author{
Abdul Haslim Abdul Shukor Lim ${ }^{1 *}$, Zulhilmi Ismail, Mohamad Hidayat Jamal, and Md. \\ Ridzuan Makhtar \\ ${ }^{1}$ Department of Water and Environmental Engineering, Faculty of Civil Engineering, Universiti \\ Teknologi Malaysia, 81310 UTM Skudai, Johor, Malaysia
}

\begin{abstract}
Capabilities of numerical tools to simulate fluid problems significantly depend on its methods to solve for the Navier-Stokes equations. Different dimensional computing tools using the same horizontal meshes were used to simulate flow conditions inside non- and vegetation meandering compound channel. Both tools give good agreement for simulations of depth-averaged streamwise velocity inside the main channel, but its capabilities vary significantly for simulations on floodplains. Lower relative depth recorded a higher percentage of errors than flow with higher relative depth. Vegetation along the main channel increased the flows complexity especially in the area near the vegetation thus reducing the simulation capabilities of the computing tools. Simulations work by TELEMAC-3D significantly better in the areas with highly dimensional and turbulence conditions. TELEMAC-2D is still useful because of its simplicity and lower computing time and resources required.
\end{abstract}

\section{Introduction}

Computational fluid dynamic (CFD) tools use numerical analysis and data structure to analyse and solve problems regarding fluid flows has been widely acknowledged and applied by engineers and researchers around the world. Improvements of these tools from time to time have increased its capabilities to tackle more complex and highly turbulence fluid conditions. There are many tools available for modeller in the market, choosing ones, depends on the modeller needs and requirements.

In this study, open source tools were used to simulate the flow properties inside a meandering compound channel. These tools, TELEMAC-2D and TELEMAC-3D are numerical modelling that solves free surface problems using finite element methods. TELEMAC-2D is a two-dimensional hydrodynamics module that solves the shallow water equations, also known as the Saint-Venant equations. Meanwhile, TELEMAC-3D is a three-dimensional hydrodynamics module with options to solve the Navier Stokes equations using the Large Eddy Simulation (LES) module. The chosen of these two

\footnotetext{
${ }^{*}$ Corresponding author: haslim1554@gmail.com
} 
modules are because of their capabilities to uses the same horizontal unstructured triangular mesh of the meandering compound channel.

TELEMAC first developed by Electricité de France-Laboratoire National d'Hydraulique et Environnement, France and now is being continuously improved and managed by a consortium of core research organisations. It already has worldwide recognition among CFD tools. TELEMAC comes with modules for sediment transport, wave, water quality and many more. TELEMAC-2D solves the fluid problems for water depth and depthaveraged velocity components inside the computational domain while TELEMAC-3D with LES option filtered smaller eddies and only solves for larger eddies as the most contributions to the Reynolds stresses comes from larger eddies. Details on the governing equations and solution sequences use in TELEMAC modules have been further discussed and explained by Hervouet and van Haren [1] and from the user manuals [2,3].

An existing meandering compound channel in the Hydraulics and Hydrology Laboratory, Universiti Teknologi Malaysia, Skudai were modelled numerically for nonvegetated floodplain (NVF) and vegetated floodplain (VF) along the main channel. Meandering compound channel flows on two different water depths were simulated for both non- and vegetated cases. Details on the modelled physical meandering compound channel can be found in the works by Ibrahim [4]. Comparisons between simulations of the depth-averaged streamwise velocity by TELEMAC-2D and TELEMAC-3D for non- and vegetation meandering compound channel will be discussed and presented here in this paper.

\section{Modelling meandering compound channel}

The compound channel consists of one main channel and two floodplains. The main channel has three and quarter wavelength with the sinuosity of 1.374 . In the vegetated cases, vegetation placed on the left-hand side floodplain along the main channel for about one wavelength of the main channel. Two-line staggered steel rod with a diameter of $0.005 \mathrm{~m}$ represents the emergent vegetation inside the compound channel. Experimental measurements have been collected at several cross-sections in the latter half wavelength of the vegetation area as shown in Fig. 1.

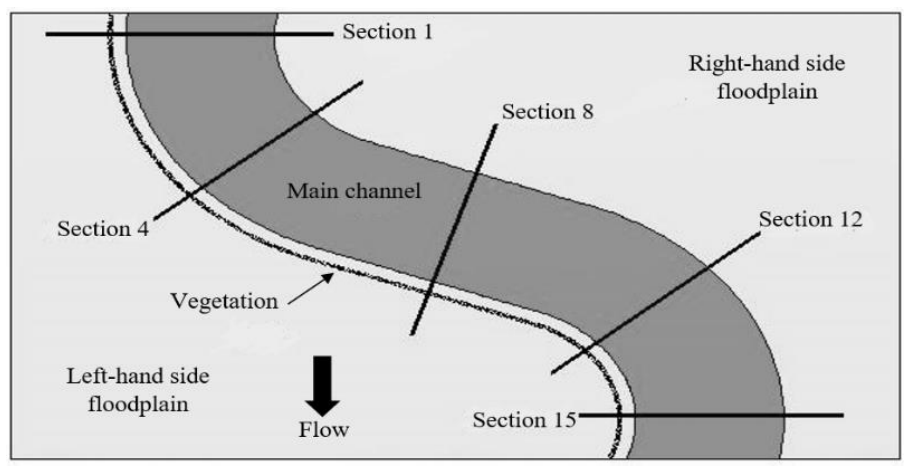

Fig. 1. Measurements sections on the meandering compound channel.

TELEMAC-2D and TELEMAC-3D used the same unstructured triangular meshes generated horizontally over the compound channel. These horizontal meshes will be duplicated by TELEMAC-3D to build prismatic elements for the three-dimensional numerical solutions [5-8]. Numbers of the horizontal layer for the three-dimensional model depends on the user specifications divided from the free surface to the channel bottom. Total of 12 layers of horizontal planes for the TELEMAC-3D are kept between over- 
discretised on the floodplains and under-discretised in the main channel. Detail on the meshes is shown in Table 1. Denser meshes generated in the area near the vegetation to capture in details the effects of vegetation, but in others area, coarser meshes were generated to optimise the computing cost for the compound channel.

Streamwise velocity at the same point in each of these horizontal layers from the simulations by TELEMAC-3D will later be averaged to compare with the streamwise velocity simulations at the same point by TELEMAC-2D. Comparisons of the experimental with these simulations will be presented here at several measurement sections inside the main channel and $0.2 \mathrm{~m}$ from the interface of the main channel-floodplain on the floodplains. Distance $0 \mathrm{~m}$ to $0.2 \mathrm{~m}$ represents the area on the left-hand side floodplain, distance $0.2 \mathrm{~m}$ to $0.7 \mathrm{~m}$ represents area inside the main channel and distance from $0.7 \mathrm{~m}$ to $0.9 \mathrm{~m}$ represents the area on the right-hand side floodplain.

Table 1. Mesh details for simulation cases.

\begin{tabular}{|c|c|c|c|c|c|}
\hline \multirow{2}{*}{ Case } & \multicolumn{2}{|c|}{$\begin{array}{c}\text { TELEMAC-2D mesh } \\
\text { (Triangular element) }\end{array}$} & \multicolumn{2}{c|}{$\begin{array}{c}\text { TELEMAC-3D mesh } \\
\text { (Prismatic element) }\end{array}$} & $\begin{array}{c}\text { No. of } \\
\text { horizontal } \\
\text { planes }\end{array}$ \\
\cline { 2 - 5 } & Total nodes & $\begin{array}{c}\text { Total } \\
\text { elements }\end{array}$ & Total nodes & $\begin{array}{c}\text { Total } \\
\text { elements }\end{array}$ & 12 \\
\hline NVF DR0.30 & 22915 & 42246 & 274980 & 484037 & 12 \\
\hline NVF DR0.45 & 22915 & 42246 & 274980 & 484037 & 12 \\
\hline VF DR0.30 & 86826 & 166136 & 1041912 & 1827496 & 12 \\
\hline VF DR0.45 & 86826 & 166136 & 1041912 & 1827496 & \\
\hline
\end{tabular}

Two different relative depths (DR) of overbank flows of 0.30 and 0.45 for non- and vegetated floodplain simulated for the computational cases. Further details of the computational properties are shown in Table 2. The relative depth, DR of the overbank flows can be calculated using:

$$
D R=\frac{H-h_{m c}}{H}
$$

where $H$ is the water depth and $h_{m c}$ is the height of the main channel.

Table 2. Simulation properties.

\begin{tabular}{|c|c|c|c|c|c|c|}
\hline Case & $\begin{array}{c}\text { Discharge, } \\
\text { Q (l/s) }\end{array}$ & $\begin{array}{l}\text { Water } \\
\text { depth, } \\
\text { H (m) }\end{array}$ & $\begin{array}{c}\text { Relative } \\
\text { depth, } \\
\text { DR }\end{array}$ & $\underset{n}{\text { Manning's, }}$ & $\begin{array}{l}\text { Sectional- } \\
\text { average } \\
\text { velocity, } U_{s} \\
(\mathbf{m} / \mathbf{s})\end{array}$ & $\begin{array}{l}\text { Time } \\
\text { step, } t \\
\text { (s) }\end{array}$ \\
\hline NVF DR0.30 & 38.0 & 0.1286 & 0.30 & 0.0142 & 0.236 & 0.01 \\
\hline NVF DR0.45 & 85.0 & 0.1636 & 0.45 & 0.0180 & 0.281 & 0.01 \\
\hline VF DR0.30 & 30.0 & 0.1286 & 0.30 & 0.0190 & 0.187 & 0.0075 \\
\hline VF DR0.45 & 48.7 & 0.1636 & 0.45 & 0.0320 & 0.183 & 0.0075 \\
\hline
\end{tabular}

Simulation cases try to mimic the uniform flow conditions as the physical experiments. Initial and boundary conditions were predetermined to resemble the actual flow conditions. Streamwise velocity normalised to the sectional-average velocity, $U_{s}$ at each of their specific cases for the depth-averaged streamwise velocity to be in dimensionless values for better comparisons between both relative depths. The sectional-average velocity, $U_{s}$ can be calculated using:

$$
U_{s}=Q / A
$$


where $Q$ is the discharge and $A$ is the cross-sectional area of the compound channel at bend apex.

\section{Results and discussions}

\subsection{Calibration and validation}

Gradients of the simulation free surface profiles at the centre of the meandering compound channel and outside of the meander belt compared with the free surface profiles of the experimental for the calibration process. Adjustments to the roughness coefficient of the compound channel being made for the simulation cases to closely resemble the uniform flow conditions of the experiment.

Validations of the non-vegetation simulation cases done by comparing the streamwise velocity of the measured and the simulate inside the main channel at measurement sections at bend apex, in these cases, at measurement Section 1 and Section 15. The same validation processes repeated for vegetation cases of both relative depths. More details on the calibration and validation processes can be found in works by Shukla [9] and Rameshwaran [10].

\subsection{Depth-averaged streamwise velocity in the main channel}

There are limitations when using the Acoustic Doppler velocimeter to measures the streamwise velocity near a wall and $0.05 \mathrm{~m}$ below the water surface makes it harder to give accurate measurement values near the main channel walls and on the floodplains for low relative depth. Therefore, only physical measurements of the main channel were presented here for non- and vegetation cases of low relative depth, DR0.30.

The patterns of TELEMAC-2D simulations for normalised depth-averaged streamwise velocity across the compound channel of the non- and vegetation cases are shown in Fig. 25. These simulations are quite similar for both relative depths. These similarities also picked up by the TELEMAC-3D simulations for the normalised depth-averaged velocity of the non- and vegetation cases for both relative depth cases.

Simulations by TELEMAC-2D for streamwise velocity at measurement Section 8 for non- and vegetation cases of low relative depth were significantly higher than the simulations for rest of the measurement sections. These higher values by TELEMAC-2D also recorded for non- and vegetation cases of high relative depth at the same measurement Section 8 . High values of streamwise velocity by TELEMAC-2D recorded at almost ten times from the measured for the non-vegetation case of DR0.30. The highest streamwise velocity value by TELEMAC-2D for vegetation case DR0.30 is at 161.4 per cent, for nonvegetation case DR0.45 is at 244.7 per cent, and for vegetation case, DR0.45 is at 385.5 per cent. These highest values by the computing tools happen to be near the main channel and left-hand side floodplain interface for all those cases except for vegetation case DR0.45 where it happens to be near the main channel and right-hand side floodplain interface.

TELEMAC-3D gives good agreement of the streamwise velocity inside the main channel in most of the measurement sections for all cases. The percentage of errors of the simulated streamwise velocity inside the main channel was recorded to be fewer than 15 per cent of the measured values. The most significant lower value by TELEMAC-3D recorded in measurement Section 1 of vegetation case DR0.45 with percentage of 77.9 near the main channel and left-hand side floodplain interface.

Overall, the simulations of streamwise velocity inside the main channel by both computational tools were reasonable and acceptable for both non- and vegetation cases. 
Significant higher values by TELEMAC-2D at measurement Section 8 most significantly due to the lack of capabilities of the model to perfectly capture the highly three-dimensional flows inside of the cross-over region due to the expansion and conviction of the overbank flows, plus the effect of vegetation in the vegetation cases.

a)

b)
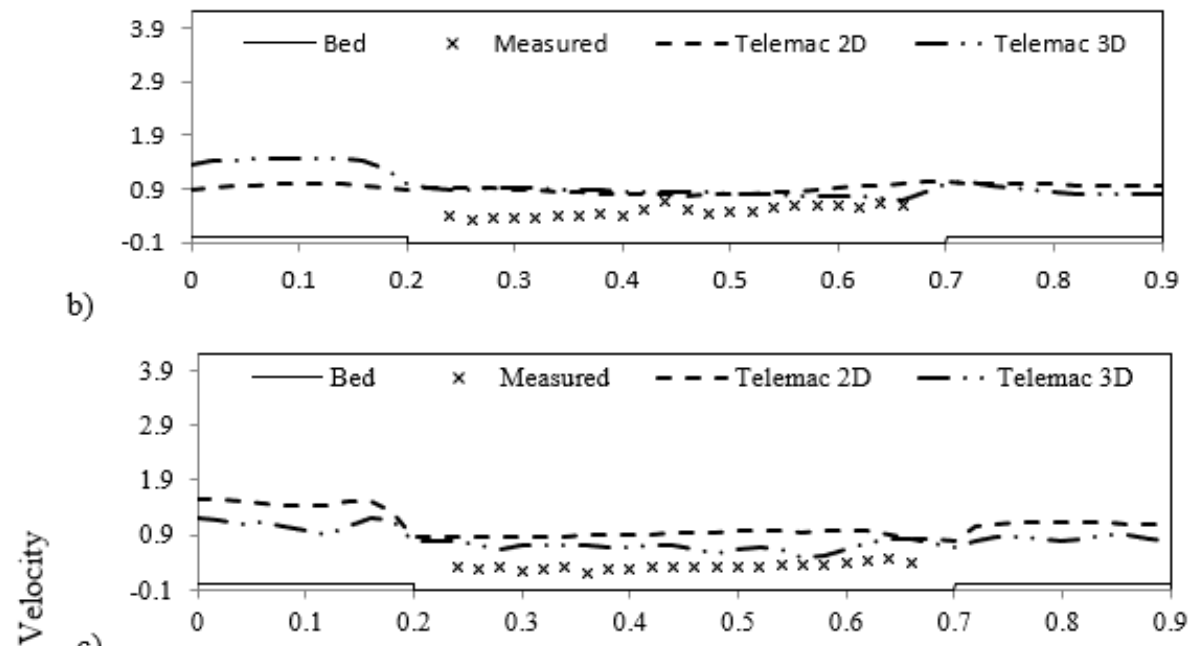

c)

d)

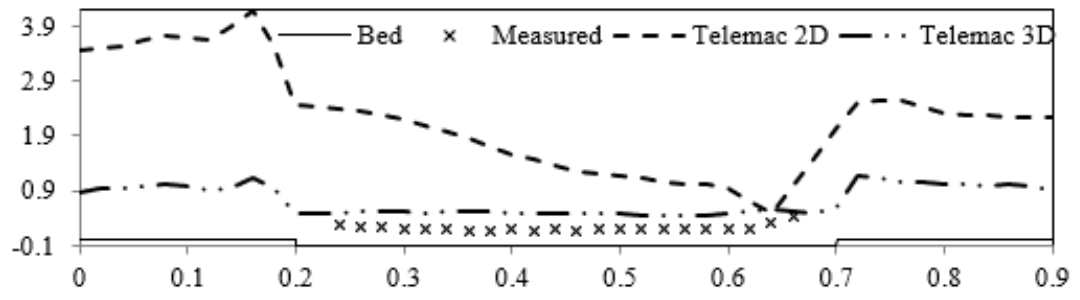

e)
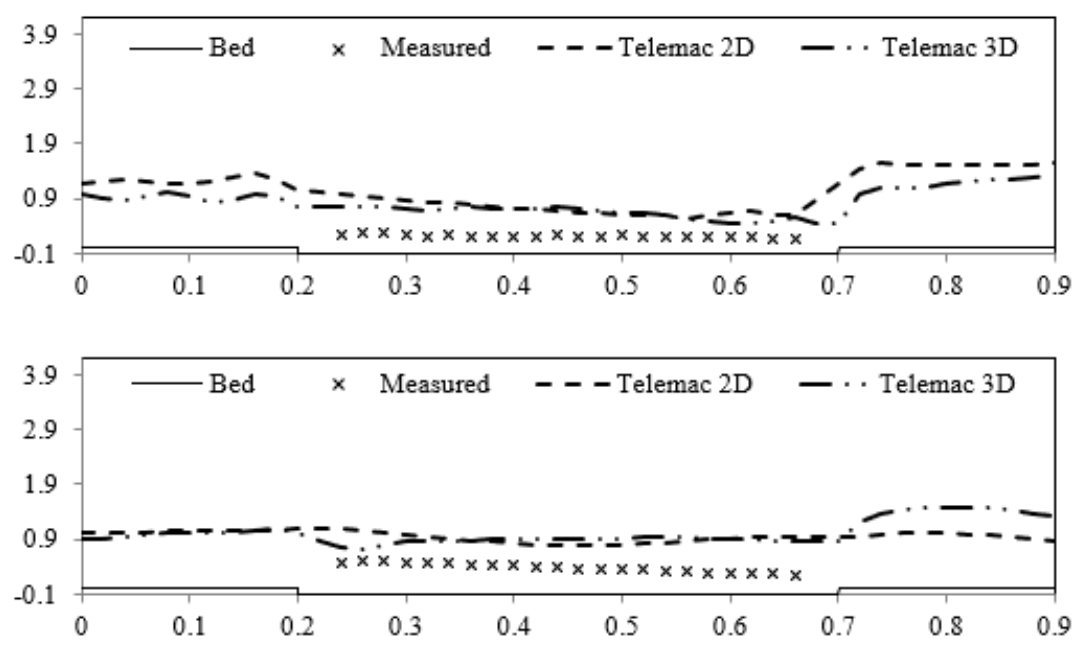

Fig. 2. Normalised depth-averaged streamwise velocity of measured, TELEMAC-2D simulations and TELEMAC-3D simulations for measurement section; a) Section 1, b) Section 4, c) Section 8, d) Section 12 and e) Section 15 of the non-vegetated case of DR 0.30 . 
a)

b)
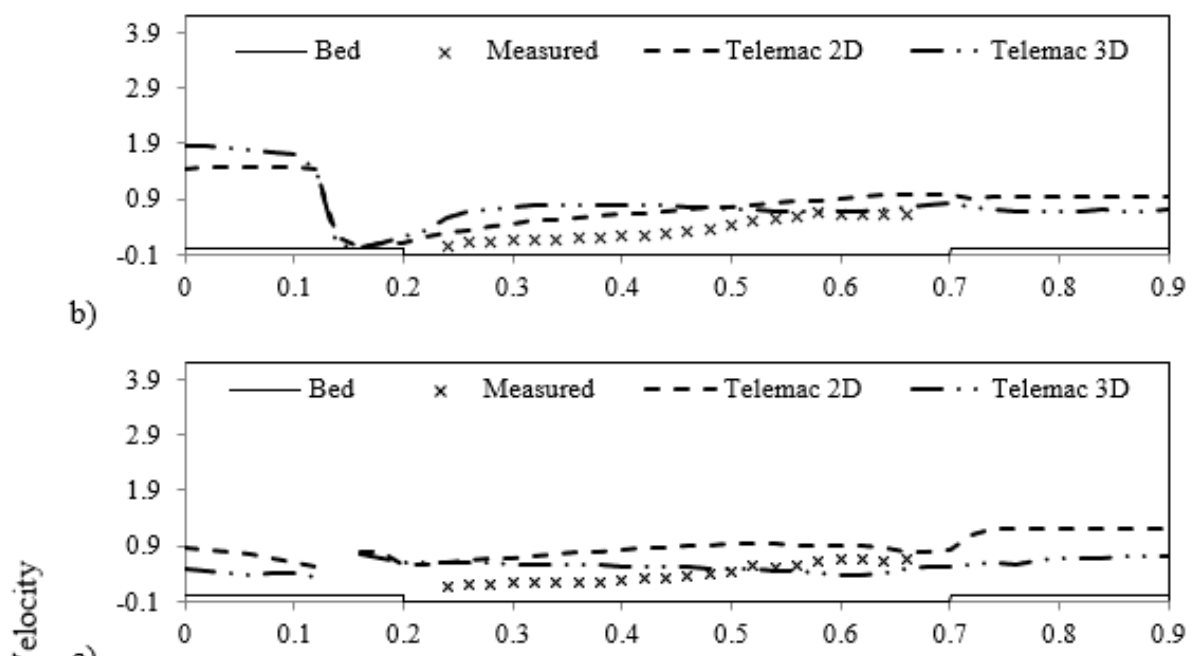

c)

m

d)
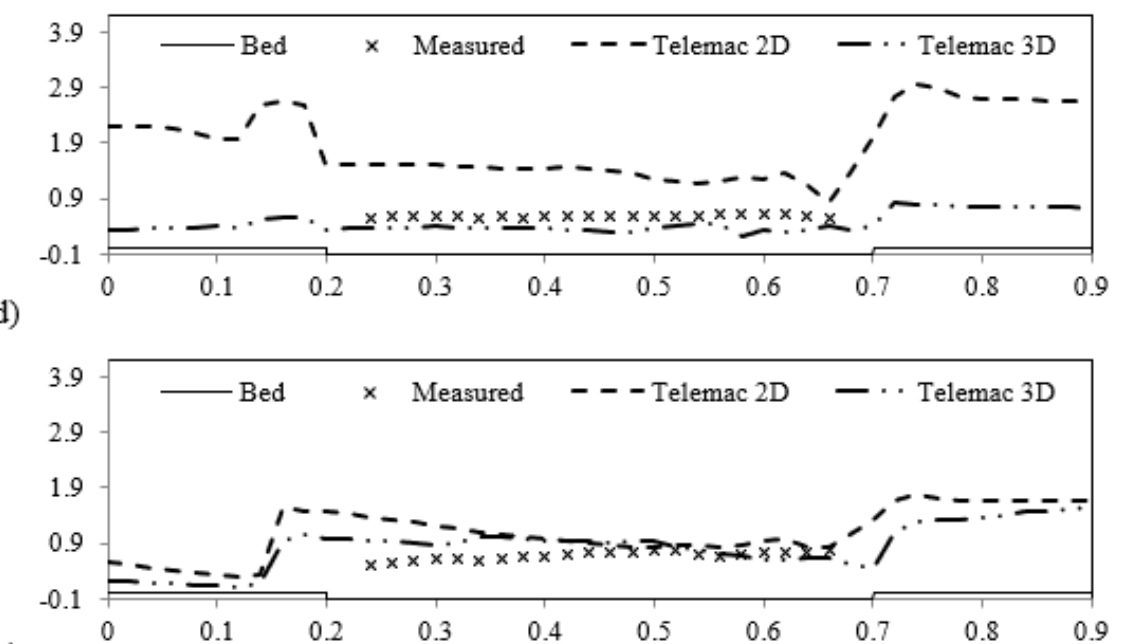

e)

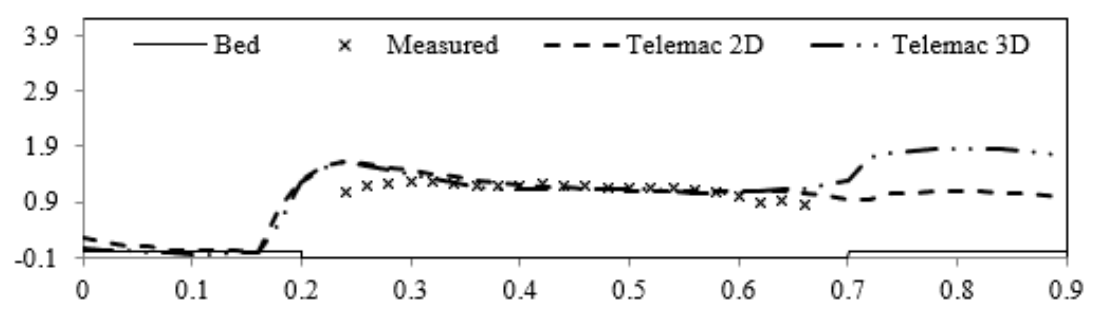

Fig. 3. Normalised depth-averaged streamwise velocity of measured, TELEMAC-2D simulations and TELEMAC-3D simulations for measurement section; a) Section 1, b) Section 4, c) Section 8, d) Section 12 and e) Section 15 of the vegetated case of DR 0.30 . 
a)

b)
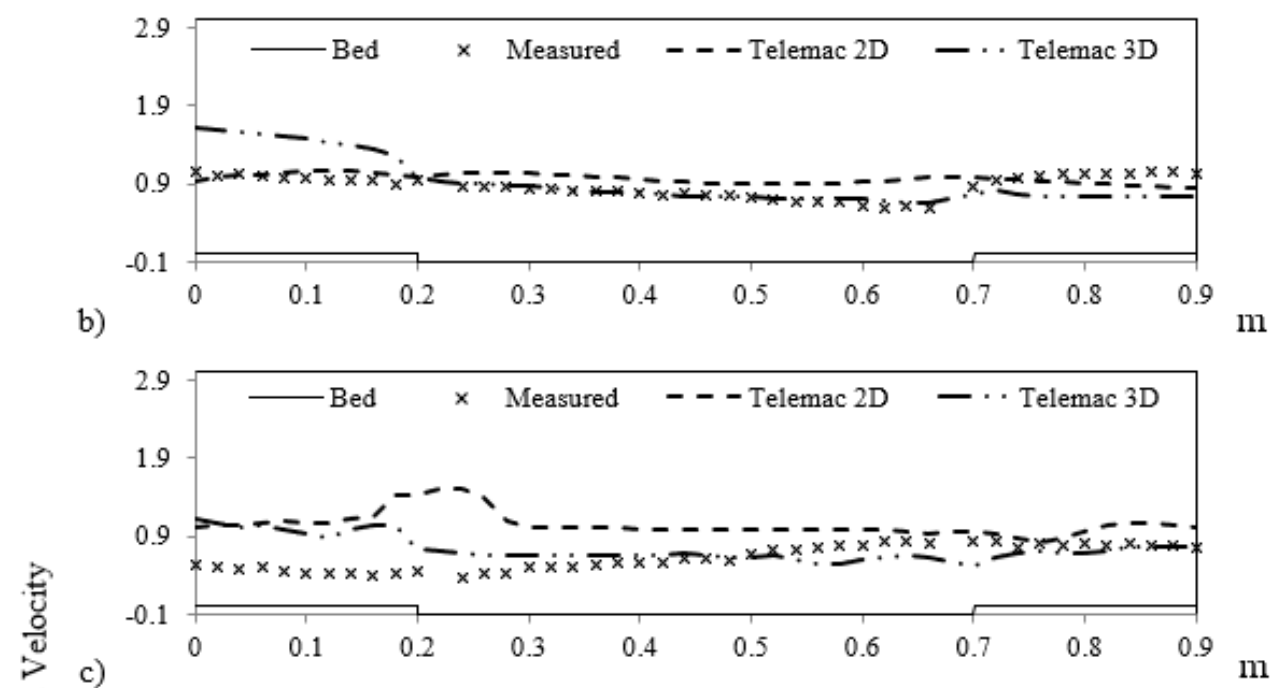

d)
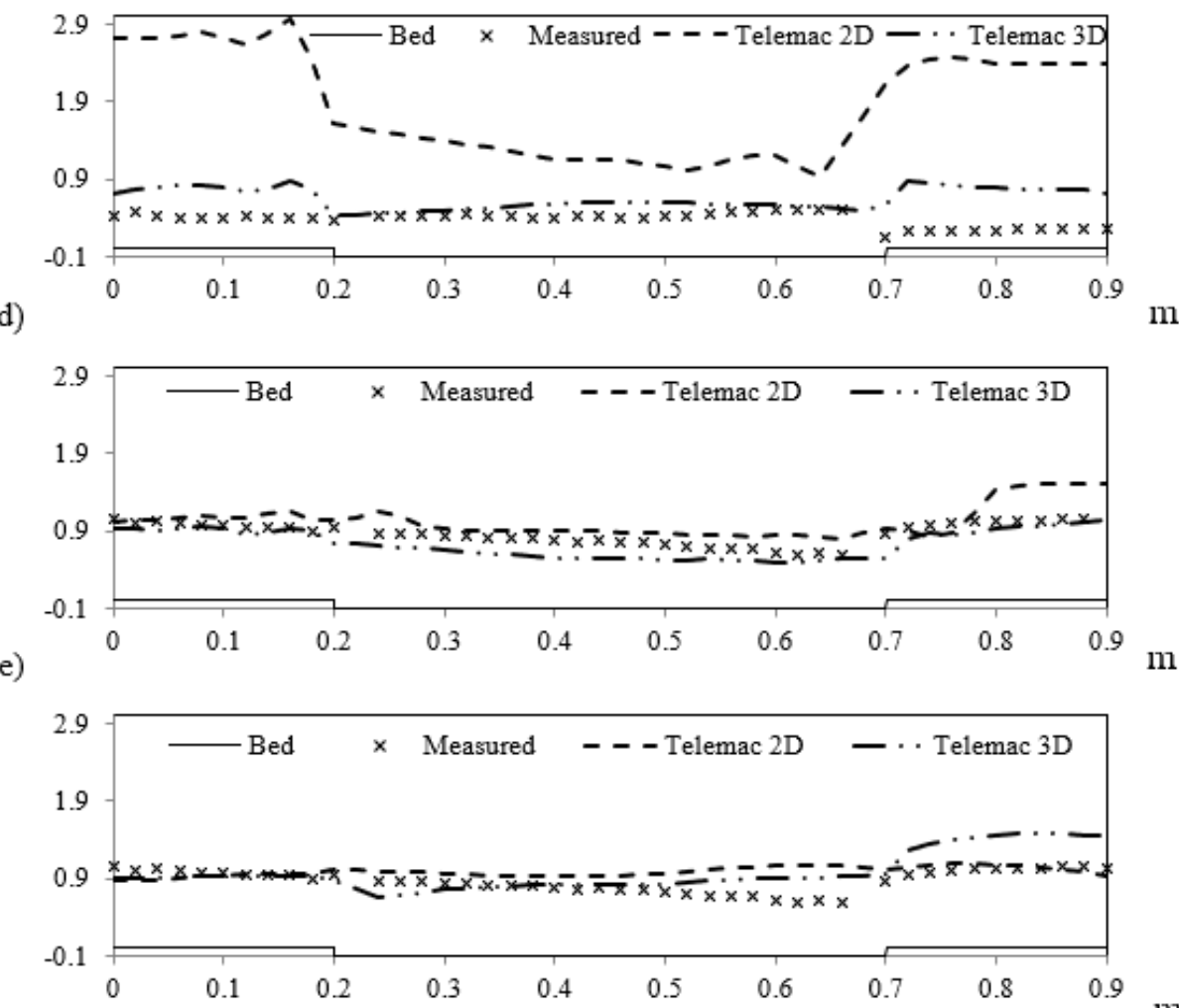

Fig. 4. Normalised depth-averaged streamwise velocity of measured, TELEMAC-2D simulations and TELEMAC-3D simulations for measurement section; a) Section 1, b) Section 4, c) Section 8, d) Section 12 and e) Section 15 of the non-vegetated case of DR 0.45 . 
a)

b)
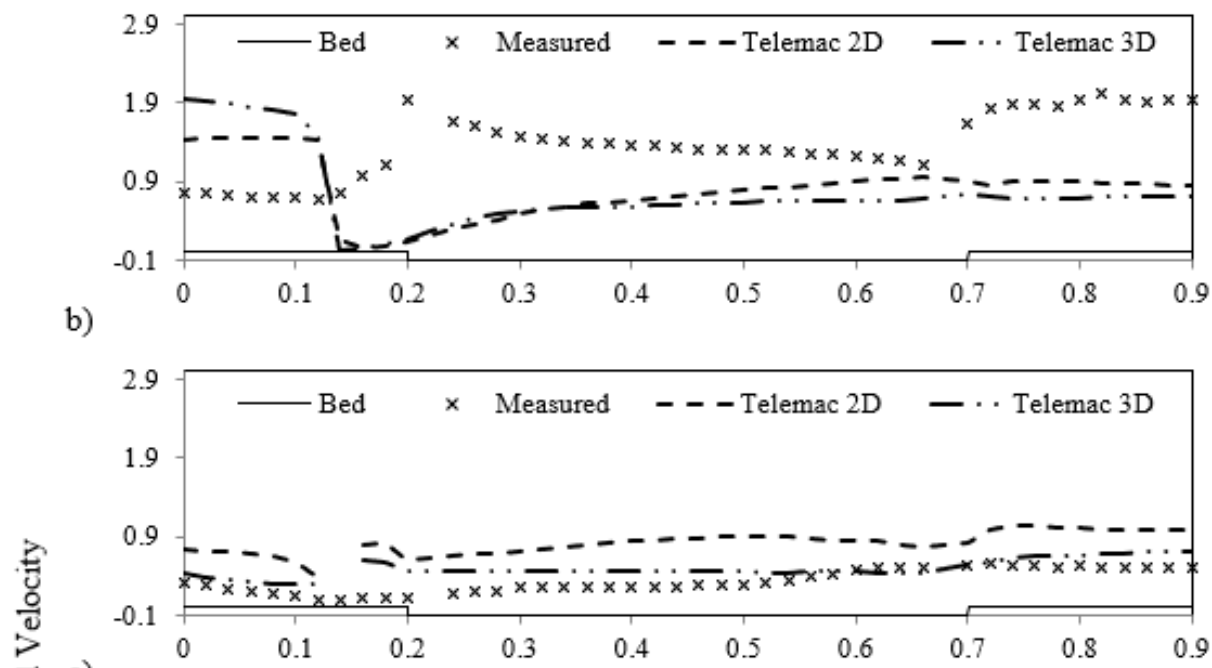

$\mathrm{m}$

c)

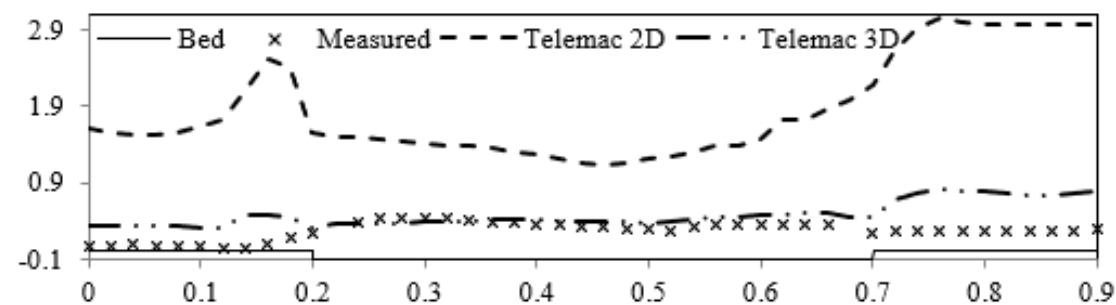

d)

e)
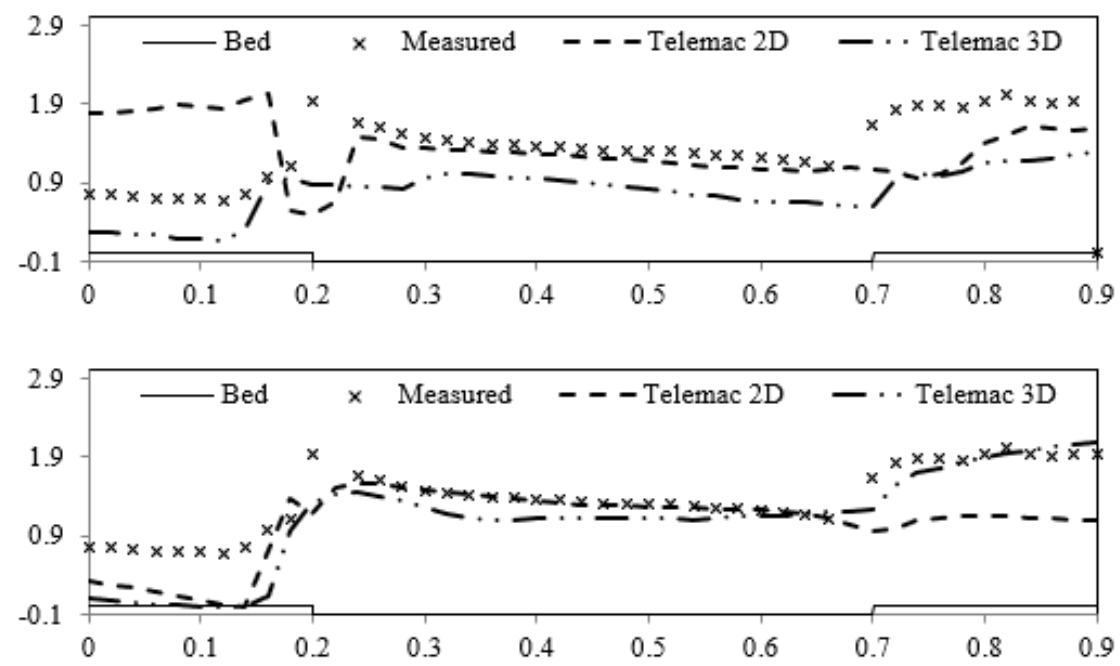

Fig. 5. Normalised depth-averaged streamwise velocity of measured, TELEMAC-2D simulations and TELEMAC-3D simulations for measurement section; a) Section 1, b) Section 4, c) Section 8, d) Section 12 and e) Section 15 of the vegetated case of DR 0.45. 


\subsection{Depth-averaged streamwise velocity on floodplains}

The measured streamwise velocity on the floodplains for low relative depth, DR0.30 was not available due to the measuring devices limitations. Therefore, discussion on the simulations of the streamwise velocity for relative depth DR0.30 on the floodplains will roughly base on the results from the high relative depth cases due to the similarities of simulations shown inside the main channel. Discussions of the streamwise velocity on the floodplains divided into left- and right-hand side floodplain.

Simulations on the left-hand side floodplain by the numerical tools seem to have higher values of the streamwise velocity in most of the measurement section of the non- and vegetation cases. Several lower values of streamwise velocity only spotted at measurement Section 12 and Section 15 by TELEMAC-3D and only at Section 15 by TELEMAC-2D for the vegetation cases. The most apparent lower values by TELEMAC-2D were shown at measurement Section 8 for both cases on the left-hand side floodplain. Simulations by TELEMAC-3D for this floodplain seems to be in good agreements with the measured although some lower values still recorded for the overbank flows protected by the vegetation. These results showed that TELEMAC-3D still cannot correctly simulate changes in flow properties due to the presence of vegetation along the main channel.

On the right-hand side floodplains, simulations by TELEMAC-3D gives better agreements with measured streamwise velocity when compares with simulations by TELEMAC-2D for the non-vegetation case. Higher values were recorded at measurement Section 8 by TELEMAC-3D but the most significant high values still given by TELEMAC$2 \mathrm{D}$ at the same measurement section in this case. The same high values pattern by TELEMAC-2D also spotted for the vegetation case at measurement Section 8 and Section 4 but lower values of the streamwise velocity at the rest of the measurement sections. Simulations by TELEMAC-3D at most of the sections seems to be in good agreements with measured streamwise velocity except at measurement Section 1 and Section 12 where the percentage of error was higher than the simulations given by TELEMAC-2D.

Section 4 recorded higher percentages of simulations errors by TELEMAC-2D on the floodplains with the highest was almost 13 times from the measured for the non-vegetation case on the right-hand side floodplain and about 44 times from the measured on left-hand side floodplain for the vegetation case. The same location on the floodplains for non- and vegetation cases also recorded the highest percentage of error for simulations by TELEMAC-3D, 2.7 times for non-vegetation case and nine times for vegetation case.

TELEMAC-3D gives good agreements of the streamwise velocity on the floodplains than TELEMAC-2D for non- and vegetation cases especially at measurement sections with highly three-dimensional and turbulence overbank flows. Interactions between overbank and in bank flow, especially in the cross-over regions, make the flows to be highly turbulence thus difficult for a just two-dimensional model to give good agreements with the measurement. In the presence of vegetation, the flow becomes more turbulence than before thus higher dimensional computational fluid dynamic simulation tools requires for a better understanding of the fluid problems.

\section{Conclusions}

Simulations of the streamwise velocity by TELEMAC-3D for the non- and vegetation cases of the meandering compound channel gives better agreements with the physical measurements rather than the simulations by TELEMAC-2D. TELEMAC-3D have higher computing capabilities than TELEMAC-2D for flows inside the meandering compound channel especially in the cross-over regions that already known to be highly threedimensional with turbulence conditions. These tools gave higher percentages of error for 
cases with lower relative depth then higher relative depth cases for flows inside the main channel. Simulations of the streamwise velocity on floodplains vary due to the presence of vegetation and dimensional of the numerical tools. Vegetation on the floodplain dramatically reduces the capabilities of these tools to simulate the overbank streamwise velocity especially in the area near the vegetation.

Overall, simulations by both tools considered have good agreement with the measured for non- and vegetation case of both relative depths except in the areas that have high interactions between overbank and in bank flows inside the meandering compound channel. These interactions increased the complexity of flows inside the meandering compound channel due to various phenomenons such as momentum transfer, expansion and contraction, and also from the generation of secondary flow circulations.

Still, simulations by TELEMAC-2D can still be useful to gives early insight into the problems due to its simplicity and fewer resources requirements with extra caution to be taken before applying the results. Although TELEMAC-3D gives better agreements than TELEMAC-2D, it required higher computing capabilities and computing time to be used. Therefore, choosing one tool will depend on the user requirements and needs as higher dimensional computational fluid dynamic tools will require more resources from the user.

Acknowledgement. Authors would like to express the highest gratitude to Ministry of Higher Education and Faculty of Civil Engineering, UTM for funding and providing their facilities for this research respectively.

\section{References}

1. J. -M. Hervouet, L. van Haren, Floodplain Processes, Ch. 6, 183-214 (1996)

2. open Telemac-Mascaret, Telemac-2D: User manual (2014). Retrieved from http://www.opentelemac.org/downloads/MANUALS/TELEMAC-2D/telemac2d_user_manual_en_v7p0.pdf

3. open Telemac-Mascaret, Telemac-3D: User manual (2016). Retrieved from http://www.opentelemac.org/downloads/MANUALS/TELEMAC3D/telemac3d_user_manual_v7p1.pdf

4. Z. Ibrahim, Z. Ismail, S. Harun, K. Shiono, N. M. Zuki, M. R. Makhtar, M. Jumain, M. S. A. Rahman, M. H. Jamal, Jurnal Teknologi, 78, 9-4 (2016)

5. P. Rameshwaran, K. Shiono, Proc. of the Inst. of Civil Engr.-Water Mgmt, 156, 4 (2003)

6. P. Rameshwaran, P. S. Naden, J. Hydraul. Res., 42, 6 (2004)

7. P. Rameshwaran, P. S. Naden, Proc. of the Inst. of Civil Engr.-Water Mgmt, 157, 3 (2004)

8. P. Rameshwaran, K. Shiono, J. H. Chandler, R. H. J. Sellin, Proc. of the 8th Int. Conf. on Hydro-science and Eng. (2008)

9. D. R. Shukla, K. Shiono, Proc. of the Inst. of Civil Engr.-Water Mgmt, 161, 1 (2008)

10. P. Rameshwaran, P. Naden, C. A. M. E. Wilson, R. Malki, D. R. Shukla, K. Shiono, Appl. Math. Modelling, 37, 20-21 (2013) 